\title{
TRANSFORMANDO MUROS: GRAFFITI COM ADOLESCENTES EM PRIVAÇÃO DE LIBERDADE
}

\section{Cláudia Regina Campos Rodrigues}

Universidade Estadual de Campinas

Amanda Garcez

Faculdade CESUSC

Renan De Vita Alves de Brito

Fundação Universidade Regional de Blumenau, Universidade Federal de Santa Catarina

Andréia Isabel Giacomozzi

Universidade Federal de Santa Catarina

Tathiana Reche Santa Rosa

Departamento de Administração Socioeducativo de Santa Catarina
Recebido em: 29/02/2020

$1^{\text {a }}$ revisão em: 10/12/2020

Aceito em: 04/03/2021

\section{RESUMO}

Este estudo avalia uma intervenção de oficinas de graffiti, com adolescentes em cumprimento de medida socioeducativa de privação de liberdade em um Centro de Atendimento Socioeducativo de Florianópolis (SC). As oficinas visaram promover uma intervenção artística, espaço de expressão, fortalecimento de vínculos e formação ética-estética-política dos jovens. Foram realizados seis encontros com dois grupos (ala feminina e masculina) de 5 a 15 adolescentes (13 a 18 anos), bem como reuniões com a equipe técnica e os agentes socioeducativos. Posteriormente, foram conduzidos grupos focais com os participantes, sendo realizada análise de conteúdo temática e discussão com registros de diários de campo. Os resultados indicaram contribuição para o caráter socioeducativo da medida, coerente com o Estatuto da Criança e do Adolescente, pois houve opiniões positivas e protagonismo dos adolescentes, reflexões sobre ética e a dinâmica do Centro.

Palavras-chave: adolescente em conflito com a lei; arte urbana; ética; medidas socioeducativas. 


\section{TRANSFORMING WALLS: GRAFFITI FOR TEENAGERS IN CONFLICT WITH THE LAW}

\section{ABSTRACT}

This study evaluates an intervention of graffiti workshops with teenagers who had their liberty restricted by socio-educative measures inside a Socio-educative Center in Florianopolis (Brazil). The workshops attempted to promote an artistic intervention, a space for expression, strengthening the bonds and the ethicalesthetical-political growth of the teenagers. Six meetings were made with two groups (the female, and the male ward) with 5 to 15 teenagers (13 to 18 years old), as well as meetings with the technical team and the socio-educative agents. Afterwards, focal groups were conducted with the participants, with analysis of the subject theme and discussions with the field journey being made. The results pointed at contribution for the socio-educative character of the measure, coherent with the Brazilian code for the child and teenager, because there were positive opinions, the teenagers protagonism, as well as reflexions about ethics and the dynamics of the Center.

Keywords: teenager in conflict with the law; urban art; ethics; socioeducative measures. 


\section{MUROS TRANSFORMADORES: GRAFITI PARA ADOLESCENTES EN PRIVACIÓN DE LIBERTAD}

\section{RESUMEN}

Este estudio evalúa la intervención de talleres de grafiti con adolescentes que cumplen con una medida socioeducativa de privación de libertad en un Centro de Servicios Socioeducativos de Florianópolis (Brasil). Los talleres tuvieron como objetivo promover una intervención artística, un espacio de expresión, fortalecer los lazos y la formación ética-estética-política de los jóvenes. Se llevaron a cabo seis reuniones con dos grupos (ala femenina y masculina) de 5 a 15 adolescentes (13 a 18 años), así como reuniones con el equipo técnico y los agentes socioeducativos. Posteriormente, se realizaron grupos focales con los participantes, con análisis de contenido temático y discusión con registros de diario de campo. Los resultados indicaron una contribución al carácter socioeducativo de la medida, de acuerdo con el Estatuto brasileño del Niño y el Adolescente, ya que hubo opiniones positivas, protagonismo de los adolescentes, reflexiones sobre la ética y la dinámica del Centro.

Palabras clave: adolescente en conflicto con la ley; arte urbano; ética; medidas socioeducativas. 


\section{INTRODUÇÃO}

A partir da Constituição de 1988 e do Estatuto da Criança e do Adolescente [ECA] (Presidência da República, 1990), a legislação brasileira passou a seguir o princípio da proteção integral de crianças e adolescentes, vistos em sua situação particular de desenvolvimento. Abrangendo toda e qualquer pessoa com menos de 18 anos, o ECA representa um avanço em relação à perspectiva do Código de Menores (Presidência da República, 1927). Esta legislação antecedente restringia seu foco a jovens em situação irregular (menores abandonados ou delinquentes), dava ênfase ao aspecto sancionatório e (re)produzia concepções estigmatizantes sobre o tema.

De acordo com o artigo 104 do ECA (Presidência da República, 1990), crianças e adolescentes são inimputáveis penalmente. Não obstante, no caso de atos infracionais, é prevista a possibilidade da aplicação de medidas socioeducativas, além das medidas de proteção cabíveis em situações concomitantes de violação de seus direitos. Segundo o Sistema Nacional de Atendimento Socioeducativo [SINASE] (Presidência da República, 2012), as medidas socioeducativas têm como objetivos: 1) a responsabilização do adolescente quanto às consequências do ato, 2) a integração social do jovem e garantia de seus direitos individuais e sociais (por meio de plano individual de atendimento) e 3) a desaprovação da conduta infracional.

São indicados seis tipos de medidas (Presidência da República, 1990): advertência, obrigação de reparar o dano, prestação de serviços à comunidade, liberdade assistida, regime de semiliberdade e internação em estabelecimento educacional. Esta última trata-se da medida mais severa reservada aos casos mais graves, podendo o adolescente ser privado de liberdade por até 3 anos. Ademais, os adolescentes poderão ser privados de liberdade por até 45 dias, por medida cautelar, antes da decisão judicial (internação provisória).

Contudo, ainda há diversos desafios a serem enfrentados para a promoção de ações de caráter socioeducativo, não consoantes com a lógica estritamente punitiva. Alguns desses desafios se relacionam a um processo social de criminalização seletiva de adolescentes pobres, bem como visão tutelar do papel do Estado e restrição de cidadania dos jovens que cometem atos infracionais (Garcia \& Pereira, 2014).

Sobre o tema, Scisleski, Bruno, Galeano, Santos e Silva (2015) apontam o paradoxo existente na cisão das medidas de proteção e socioeducativas no ECA. Tal distinção gera diferenças no tratamento jurídico e assistencial entre aqueles que tem seus direitos violados e jovens que cometem atos infracionais. Quanto às medidas socioeducativas, muitas vezes, enfoca-se apenas o nível de periculosidade e as possibilidades de reincidência dos atos infracionais. Algumas unidades de internação, inclusive, têm características que se aproximam ao sistema prisional adulto e promovem violação de direitos dos adolescentes. Um 
exemplo é a superlotação do sistema socioeducativo, que atualmente tem índice de lotação nacional de 111,9\% (Conselho Nacional do Ministério Público, 2019).

Leal e Macedo (2019) complementam tal perspectiva, ao analisar documentos e o discurso de trabalhadores de unidades de internação. Estes autores pontuam que prevalecem as práticas de disciplina, controle e ajustamento da conduta dos jovens, como se o objetivo da proteção integral se confundisse com a punição. Ao compreender os atos infracionais como fruto de escolha individual, deixa-se de lado o fato de que os jovens também se inserem em contextos vulneráveis e de violência, além da dificuldade de acesso a direitos. Em decorrência disso, ficam segundo plano os investimentos em ações de proteção e fortalecimento das famílias.

Em revisão de literatura sobre adolescentes em conflito com a lei, Mansur, Nascimento, Rosa e Merçon-Vargas (2018) destacam que, por um lado, o perfil dos adolescentes internados reflete processos de exclusão social anteriores e, por outro, a própria internação contribui para a perpetuação da marginalização e violação de direitos. Conforme o Levantamento Anual do SINASE de 2016 (Ministério dos Direitos Humanos, 2018), a maior parte dos adolescentes em privação de liberdade são homens (96\%), de 16 a 17 anos (57\%) e cor preta ou parda (59,1\%). Predominam, ainda, pessoas de classes sociais e regiões marginalizadas, com baixo grau educacional, características associadas a discriminação e preconceito, bem como maior chance de punições severas pela polícia e sistema judiciário (Mansur et al., 2018). Durante a internação, com maior frequência, são descritas práticas coercitivas, em detrimento das pedagógicas, clima hostil, estruturas inadequadas e serviços precários - condições que provocam sofrimento nos adolescentes, estigmatização e altas taxas de reincidência (Coscioni, Costa, Rosa, \& Koller, 2017).

Exemplificando um cenário local, Simões (2014) faz um diagnóstico da garantia dos direitos em 18 das 24 unidades socioeducativas (casas de semiliberdade, de internação e internação provisória) que compunham o sistema do estado de Santa Catarina em 2011 e 2012. Por meio de índices que seguem os eixos principais da ação socioeducativa (sendo aqui de relevância especial os eixos 1Suporte institucional e pedagógico, e 4- Esporte, Cultura e Lazer), foram constatadas diferenças entre o que era previsto na legislação vigente e aquilo que era ofertado na prática, bem como heterogeneidade entre as unidades.

\section{GRUPOS NO CONTEXTO SOCIOEDUCATIVO}

Diante desse cenário, propõe-se que o referencial teórico-epistemológico da Psicologia Social Crítica pode oferecer ferramentas para uma atuação comprometida com a perspectiva socioeducativa. Para tanto, é essencial considerar a singularidade do sujeito e seu contexto sócio-histórico-cultural, promover práticas que problematizem padrões normativos e opressores, valorizem a rede social e potencializem o protagonismo dos sujeitos (Gesser, 2013). Ademais, em relação à adolescência, geralmente vista como período com 
características universais e homogêneas (por exemplo, como fase de mudanças e crises geradas por fatores supostamente naturais), é imprescindível ter um olhar contextualizado, de acordo com condições e necessidades sociais e econômicas (Frota, 2007).

Visando o contexto socioeducativo, considera-se pertinente o trabalho com grupos, sendo este constituído pela atuação dos membros em um projeto comum (Lapassade, 1983). Com base em relatos de experiência de intervenções em grupo desenvolvidas com adolescentes em conflito com a lei, verifica-se que este dispositivo se trata de estratégia psicossocial com potencial transformador por promover vínculos, construção conjunta e partilha de experiências, de modo a visibilizar narrativas que são normalmente apagadas, incitar processos reflexivos e ampliar os modos de pensar e agir (Broide \& Broide, 2015; Grassi, Coltro, Giacomozzi, \& Santa Rosa, 2019; Lima-Duarte, Gaia, Torres Filho, \& Nascimento, 2019; Rodrigues \& Lopes de Oliveira, 2018; Silva \& Meira, 2014).

Nesse sentido, destaca-se a proposta de oficinas estéticas, utilizadas como ferramenta de intervenção para problematizar as relações entre os participantes/membros de um grupo, bem como investir na formação éticaestética-política (Berri, Zanella, \& Assis, 2015; Brito \& Zanella, 2017). Tais oficinas são baseadas em conceitos da ética de Spinoza (1677/2014), de acordo com a leitura de Deleuze (1970/2002), assim como exposto em Brito (2016). Dessa forma, distingue-se discursos moralizadores - nos quais há imposição da concepção previamente estabelecida de "Bem e Mal" (lógica do dever ser) - da ética das relações, entendida como um tipo de vínculo que deriva da experiência e do diálogo com o outro. São tensionadas as noções de Bem e Mal, as quais pautadas em códigos estabelecidos em realidades exteriores, para que cedam lugar às relações fundadas na fala e na escuta, e em verdades contingentes, que dizem respeito a um tempo-espaço específico. Nesta última perspectiva, nos casos em que se ignora as escolhas ou a liberdade do outro (maus encontros), há consequências às quais deve-se responder.

De tal modo, nos encontros das oficinas, busca-se criar condições para a reflexão de escolhas e suas implicações (aspecto ético), por meio de processos de criação que decorrem da desconstrução de relações cristalizadas (aspecto estético) e de posicionamentos diante de riscos e potências dos atos (aspecto político) (Brito \& Zanella, 2017). Assim, esse trabalho apoia-se em uma compreensão consoante com Simões (2014), para quem as medidas socioeducativas "devem transmitir uma nova ética através de ações pedagógicas" (Simões, 2014, p. 15).

Complementarmente, em outra perspectiva teórico-metodológica, Lima-Duarte et al. (2019) constataram que o ensino de graffiti proporcionou reflexões críticas em adolescentes de uma unidade de internação masculina, com base em uma intervenção realizada quase simultaneamente à que será relatada neste manuscrito. As estratégias utilizadas incluíram oficinas de desenho e pintura, além da leitura de imagens e filmes. A partir da intervenção, os adolescentes 
começaram a ver o graffiti como uma possível ferramenta para fazer denúncias e reivindicar direitos.

O uso do Graffiti como ferramenta psicossocial de fortalecimento do coletivo parte da prerrogativa de que, nas cidades, essa forma de expressão artística tem a potência de interferir no cotidiano das pessoas e possibilitar espaços de fala às pessoas que em geral não o têm (Almeida, 2013). Aposta-se, portanto, no graffiti como dispositivo de tensionamento do status quo em unidades de privação de liberdade de adolescentes, problematizando o controle disciplinar excessivo que geralmente ocorre, assim como os espaços de fala e de decisões institucionais, raramente designados a estes jovens.

Com base no referencial teórico exposto, este estudo tem como objetivo apresentar e analisar (por meio das anotações em diário de campo e grupos focais posteriores) oficinas de graffiti, desenvolvidas por um psicólogo e duas estagiárias de psicologia com adolescentes em um Centro de Atendimento Socioeducativo de Florianópolis (SC). Tais oficinas visaram propiciar aos jovens a apropriação da técnica do Graffiti para a criação de um projeto coletivo de intervenção artística no local; promover o fortalecimento de vínculos entre os adolescentes; criar um espaço de fala e expressão; e possibilitar a formação éticaestética-política dos jovens. Assim, espera-se contribuir com a efetivação das medidas socioeducativas de acordo com o que é previsto pelo ECA e SINASE (Presidência da República, 1990, 2012). Por meio dos grupos focais com os/as adolescentes, objetivou-se investigar a percepção dos participantes a respeito de oficinas e avaliar pontos positivos e negativos da intervenção.

\section{MÉTODO}

Foram realizadas oficinas com dois grupos de adolescentes (ala feminina e masculina), em encontros realizados durante os meses de maio e junho de 2018 com concordância e apoio da instituição, que forneceu suporte financeiro para o projeto. A presente pesquisa seguiu as diretrizes estipuladas pela Resolução $\mathrm{N}^{\circ}$ 510/2016 do Conselho Nacional de Saúde, sendo aprovada pelo Comitê de Ética em Pesquisa com Seres Humanos (CEPSH) da Universidade Federal de Santa Catarina (Parecer n. ${ }^{\circ} 2.666 .743$ de 21 de maio de 2018).

\section{PARTICIPANTES}

Em cada encontro, participaram entre cinco e quinze adolescentes, com idades de 13 a 18 anos, em cumprimento de medida socioeducativa de privação de liberdade ou internação provisória. O número de participantes por encontro variou de acordo com o número de internos na instituição (alguns entraram após o início, outros saíram antes do término), assim como o impedimento na participação de atividades daqueles que estavam em medida disciplinar aplicada por comissão do estabelecimento (nos casos de descumprimento de regras da unidade). Além disso, alguns agentes socioeducativos de plantão nas alas 
participaram das atividades em caráter eventual, de acordo com o próprio interesse.

\section{PROCEDIMENTOS}

Houve duas etapas na pesquisa: inicialmente, foram realizadas oficinas de Graffiti e, em seguida, grupos focais a respeito da percepção dos e das adolescentes sobre a experiência.

\section{PRIMEIRA ETAPA: OFICINAS DE GRAFFITI}

Foram realizados seis encontros com periodicidade semanal em cada ala (masculina e feminina), nos quais foram abordados: 1) apresentação da trajetória do psicólogo que coordenava as oficinas com Graffiti; 2) exposição de imagens (de Graffitis, pixações e outras modalidades de arte urbana) e conversa sobre arte; 3) atividade de desenho e pintura individuais, visando levantar ideias para o projeto coletivo; 4) instruções e treino da técnica de uso dos sprays (desenhos e escritos no muro); 5) pintura do muro (em preparação para o desenho); e 6) realização do graffiti. No terceiro e no sexto encontro, foram colocadas músicas de RAP selecionadas pelos coordenadores, por conterem mensagens críticas e falarem sobre o contexto de vida dos/das adolescentes. No encontro final, artistas graffiteiros voluntários foram convidados para contribuir com o graffiti feito no muro (cinco na ala feminina - sendo três mulheres, e três na masculina todos homens).

Durante a intervenção, foram propostas discussões sobre arte, cultura Hip Hop, responsabilização sobre os próprios atos e a diferença entre transgressão e subversão de normas (sendo esta última forma de tensionar e, possivelmente, gerar transformações em regras). As oficinas foram realizadas no espaço de convívio de cada ala, na própria unidade, sendo pintados os muros do solário (masculina) e no caminho para as salas de aula e biblioteca (feminina). Devido à separação das adolescentes em dois subgrupos na ala feminina (separadas por grades e o espaço de monitoria das agentes socioeducativas), os três últimos encontros da oficina ( 4 a 6 ) tiveram que ser divididos em dois momentos. A divisão da ala feminina decorreu de decisão das agentes socioeducativas, após uma rebelião que aconteceu entre 2016 ( $2^{\circ}$ semestre) e 2017 (1 semestre), sendo que os subgrupos ficam separados por grades e pelo espaço de monitoria das agentes.

Também foram realizadas reuniões com a equipe técnica e as gerências das unidades, para apresentação da proposta, antes do início das oficinas. Ao longo dos encontros, notou-se a importância de realizar um trabalho em conjunto com os agentes socioeducativos, por apresentarem resistência à proposta das oficinas. Isso ocorreu, nas duas alas, após o primeiro encontro e, na ala masculina, após o primeiro desenho nos muros para treino do uso dos sprays (que incluiu um esboço feito pelo psicólogo coordenador e pintado em conjunto com os jovens, assim como a escrita nos muros de nomes e apelidos dos adolescentes). Nessas 
duas ocasiões, os agentes se articularam para conversar com a equipe técnica e a gerência. Então, por solicitação da equipe e dos coordenadores das oficinas, após o primeiro e o quinto encontro, foram convocadas reuniões visando estabelecer um diálogo com todos os envolvidos.

Durante as reuniões, os agentes manifestaram preocupação que os discursos e reflexões propostas resultassem em confusões e rebeliões e/ou reforçassem o "crime". O coordenador das oficinas, apoiado pela psicóloga da unidade, demonstrou-se aberto ao diálogo, explicou e defendeu a perspectiva teórica (ética-estética-política) do projeto. Reforçou, ainda, a importância do trabalho coletivo, envolvendo participação do maior número possível de pessoas da instituição, para se obter um potencial socioeducativo mais amplo. Também foi negociado sobre as ideias de desenho propostas pelos/as adolescentes e os espaços que seriam pintados. A principal restrição acordada se referia a dizeres que remetessem às facções e desenhos com significados de violência.

Durante as oficinas, as atividades foram pensadas ao longo do processo, de maneira engajada e dialógica com os participantes. Todo o percurso foi registrado em diários de campo - os quais serviram de substrato para a reflexão das práticas e planejamento das oficinas.

\section{SEGUNDA ETAPA: GRUPOS FOCAIS}

Com o intuito de realizar uma reflexão sobre a experiência, foram realizados grupos focais com os/as adolescentes que participaram da oficina em cada ala. Nessa ocasião, a pesquisa foi apresentada e cada adolescente assinou um Termo de Assentimento (o Termo de Consentimento Livre e Esclarecido foi assinado pela Juíza responsável). A conversa teve como disparador uma apresentação em slides (no programa PowerPoint do pacote Office), com descrições breves de cada encontro das oficinas e imagens, quando disponível. O registro do áudio deste encontro foi autorizado somente na ala masculina, sendo que na feminina foram realizadas anotações durante o grupo por uma das estagiárias. Nesta ala, o psicólogo não pode comparecer, sendo o grupo coordenado apenas pelas estagiárias.

Com base na transcrição do material (ala masculina), foi feita uma preparação do texto: retirou-se aquilo que não tinha relação com as oficinas e as falas dos coordenadores (utilizadas apenas para verificação do contexto de análise). Prosseguiu-se uma separação em proposições com sentido isolável (unidade de análise), sem que fosse feita distinção entre os participantes. Então, foi realizada uma análise de conteúdo categorial do material (Bardin, 1977), de modo que foram criadas categorias temáticas gerais e específicas (verificando frequências e porcentagens), por meio do agrupamento por semelhança. Foi feito processo semelhante com as anotações fruto do grupo focal da ala feminina, com a especificidade de que as unidades de análise foram os temas anotados, sem a demarcação de frequências. 


\section{RESULTADOS E DISCUSSÃO}

\section{ALA MASCULINA}

A partir do diário de campo, foi possível constatar que a intervenção promoveu o compartilhamento de experiências dos adolescentes com arte urbana e com regras em diferentes contextos (em grupos ligados à criminalidade, na instituição socioeducativa e entre si). Também foi proporcionado espaço para posicionamentos dos jovens em conversas e negociações com a equipe. Por outro lado, alguns tensionamentos que surgiram durante o processo não foram abordados explicitamente nas oficinas, emergindo apenas no grupo focal.

Quanto à arte final (Figura 1), dois dos graffiteiros convidados fizeram uma paisagem com pássaros e um triângulo preto com planetas ao centro e alguns bombs (letras grandes preenchidas) com suas assinaturas, enquanto outro fez uma mandala e o coordenador da oficina fez o painel com palavras imitando paredes pixadas e um pássaro (semelhante ao realizado durante o treino dos sprays). A ideia de desenhar a mandala partiu de um dos jovens, motivando o coordenador a convidar um graffiteiro com tal especialidade.

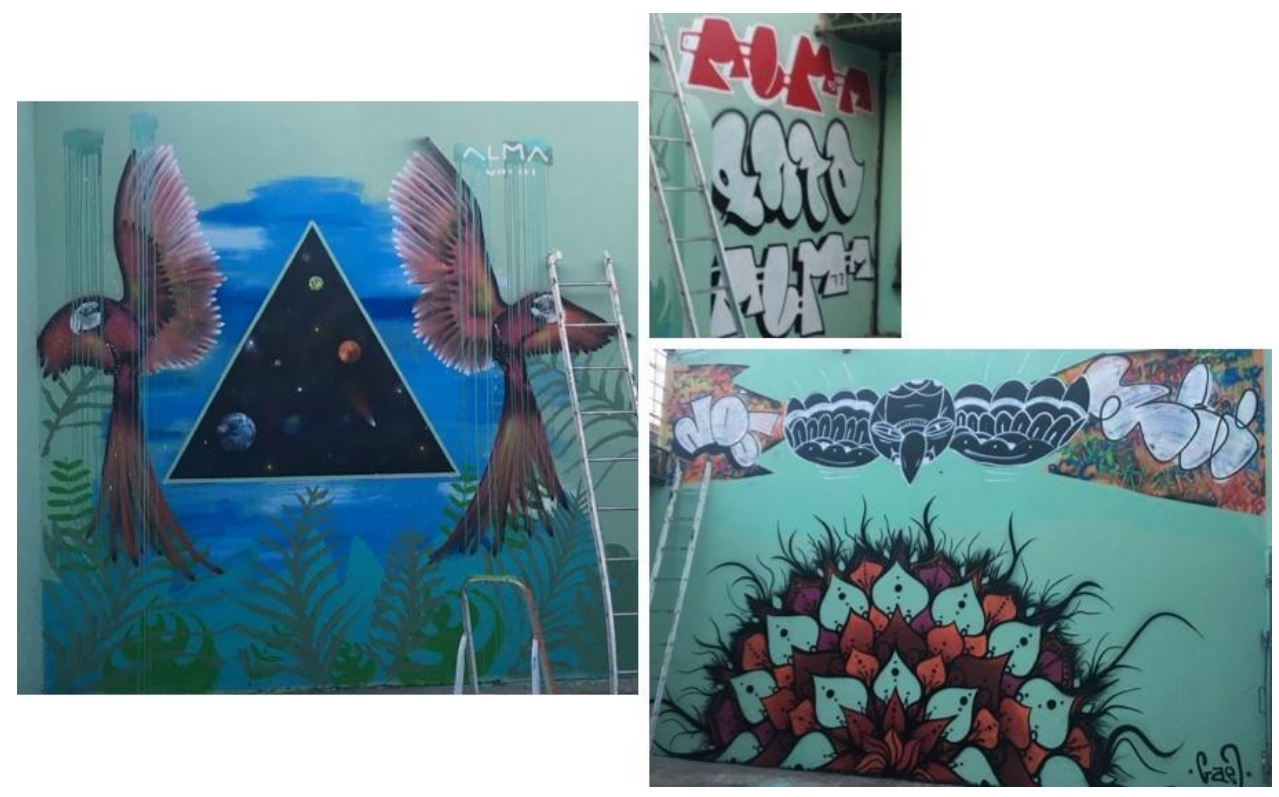

\section{Figura 1.}

Graffitis realizados na ala masculina. Nas imagens da esquerda e superior direita, o trabalho conjunto de Alma e Quinto. Na direita inferior, o trabalho do coordenador com os adolescentes (superior) e de Gael (inferior).

Os adolescentes contribuíram com os desenhos em partes específicas (principalmente no preenchimento de partes dos desenhos) e com as palavras no painel. O maior número de adolescentes e menor quantidade de desenhos parece ter contribuído para a menor participação dos jovens na execução do graffiti. Não obstante, todos pareciam bastante envolvidos com a atividade, interagindo com os convidados ou observando atentamente. Outros detalhes 
registrados em diário de campo serão articulados às categorias decorrentes da análise de conteúdo temática do grupo focal masculino (Tabela 1).

\section{Tabela 1.}

Frequências e porcentagens (\%) de ocorrência categorias de análise do grupo focal na ala masculina.

\begin{tabular}{|c|c|c|c|}
\hline Categoria & Subcategoria & Frequência & $\%$ \\
\hline \multirow{3}{*}{$\begin{array}{l}\text { Opinião geral sobre } \\
\text { as oficinas }\end{array}$} & Opinião positiva & 5 & $4,13 \%$ \\
\hline & "Distrair a mente" & 1 & $0,83 \%$ \\
\hline & Tensionamento ou ambiguidade & 6 & $4,96 \%$ \\
\hline \multirow{3}{*}{ Aprendizados } & Técnica e prática do Graffiti & 5 & $4,13 \%$ \\
\hline & $\begin{array}{l}\text { Ações decorrentes da oficina } \\
\text { (podem gerar atritos) }\end{array}$ & 1 & $0,83 \%$ \\
\hline & História do Graffiti & 2 & $1,65 \%$ \\
\hline \multirow{2}{*}{$\begin{array}{c}\text { Visão dos } \\
\text { adolescentes sobre } \\
\text { o coordenador }\end{array}$} & $\begin{array}{l}\text { 1a impressão sobre o } \\
\text { coordenador (apreensivo) }\end{array}$ & 2 & $1,65 \%$ \\
\hline & Opinião positiva ("louco") & 2 & $1,65 \%$ \\
\hline \multirow{2}{*}{$\begin{array}{l}\text { Papel ativo dos } \\
\text { adolescentes }\end{array}$} & $\begin{array}{c}\text { Ações de dominância dos } \\
\text { adolescentes }\end{array}$ & 5 & $4,13 \%$ \\
\hline & $\begin{array}{c}\text { Ações dos adolescentes nas } \\
\text { oficinas }\end{array}$ & 7 & $5,79 \%$ \\
\hline \multirow{4}{*}{$\begin{array}{l}\text { Comentário sobre a } \\
\text { apresentação } \\
\text { (PowerPoint) }\end{array}$} & $\begin{array}{l}\text { Opinião positiva sobre a arte do } \\
\text { Graffiti }\end{array}$ & 3 & $2,48 \%$ \\
\hline & $\begin{array}{l}\text { Opinião positiva sobre desenhos } \\
\text { (encontro } 3)\end{array}$ & 3 & $2,48 \%$ \\
\hline & $\begin{array}{l}\text { Coletividade entre os } \\
\text { adolescentes }\end{array}$ & 1 & $0,83 \%$ \\
\hline & $\begin{array}{l}\text { Distinção entre adolescentes e } \\
\text { agentes socioeducativos }\end{array}$ & 2 & $1,65 \%$ \\
\hline \multirow{4}{*}{ Relação com o crime } & $\begin{array}{l}\text { Menção à vida "lá fora" } \\
\text { ("mundão") }\end{array}$ & 5 & $4,13 \%$ \\
\hline & $\begin{array}{l}\text { Riscos do envolvimento com o } \\
\text { crime }\end{array}$ & 7 & $5,79 \%$ \\
\hline & $\begin{array}{l}\text { Tentativa de sair da vida do } \\
\text { crime }\end{array}$ & 4 & $3,31 \%$ \\
\hline & Regras do mundo do crime & 2 & $1,65 \%$ \\
\hline
\end{tabular}


Tabela 1. Continuação.

\begin{tabular}{|c|c|c|c|}
\hline Categoria & Subcategoria & Frequência & $\%$ \\
\hline \multirow{5}{*}{$\begin{array}{l}\text { Acordos coletivos e } \\
\text { tensionamentos }\end{array}$} & $\begin{array}{c}\text { Acordos gerais a respeito das } \\
\text { oficinas }\end{array}$ & 6 & $4,96 \%$ \\
\hline & $\begin{array}{c}\text { Descumprimento dos acordos } \\
\text { coletivos }\end{array}$ & 4 & $3,31 \%$ \\
\hline & $\begin{array}{l}\text { Tensionamento por parte dos } \\
\text { agentes (broncas e ameaças) }\end{array}$ & 5 & $4,13 \%$ \\
\hline & $\begin{array}{c}\text { Acordo coletivo entre o grupo } \\
\text { de adolescentes }\end{array}$ & 4 & $3,31 \%$ \\
\hline & $\begin{array}{l}\text { Na possibilidade que novas } \\
\text { oficinas venham a acontecer... }\end{array}$ & 4 & $3,31 \%$ \\
\hline \multirow{6}{*}{$\begin{array}{l}\text { Suposições sobre a } \\
\text { impossibilidade de } \\
\text { cumprir o } \\
\text { combinado }\end{array}$} & Dúvidas sobre o assunto & 1 & $0,83 \%$ \\
\hline & $\begin{array}{l}\text { Equipe técnica teria } \\
\text { descumprido }\end{array}$ & 1 & $0,83 \%$ \\
\hline & $\begin{array}{c}\text { Contra a culpabilização da } \\
\text { Equipe técnica }\end{array}$ & 4 & $3,31 \%$ \\
\hline & $\begin{array}{l}\text { Agentes socioeducativos teriam } \\
\text { descumprido }\end{array}$ & 2 & $1,65 \%$ \\
\hline & $\begin{array}{c}\text { Visão negativa dos agentes } \\
\text { sobre as oficinas }\end{array}$ & 6 & $4,96 \%$ \\
\hline & $\begin{array}{l}\text { Visão positivas dos agentes } \\
\text { sobre os graffitis (posterior) }\end{array}$ & 3 & $2,48 \%$ \\
\hline \multirow{4}{*}{$\begin{array}{l}\text { Opinião sobre os } \\
\text { Graffitis finais }\end{array}$} & Opinião positiva dos desenhos & 6 & $4,96 \%$ \\
\hline & Opinião negativa dos desenhos & 3 & $2,48 \%$ \\
\hline & Confusão com os desenhos & 2 & $1,65 \%$ \\
\hline & Reflexão a partir dos desenhos & 3 & $2,48 \%$ \\
\hline \multirow{3}{*}{ Outros } & Comentários sobre autoimagem & 2 & $1,65 \%$ \\
\hline & Menção à liberdade & 1 & $0,83 \%$ \\
\hline & Opiniões sobre os convidados & 1 & $0,83 \%$ \\
\hline TOTAL & & 121 & $100 \%$ \\
\hline
\end{tabular}

A maior parte das categorias demonstrou opiniões bastante positivas dos adolescentes a respeito das oficinas. Podem ser citadas, nesse sentido, a categoria Opinião positiva (geral sobre as oficinas), com 4,13\% $(n=5)$, assim como Opiniões positivas na Visão dos adolescentes sobre o coordenador, com 1,65\% $(n=2)$. Também foram relatados aprendizados, sobre Técnica e prática do Graffiti com 4,13\% ( $n=5)$ e sobre História do Graffiti, com 1,65\% $(n=2)$. 
"Pra mim, tudo foi da hora". (Opinião positiva geral sobre as oficinas)

"Ah, o cara já até aprendeu a pixar, mesmo" (Aprendizados sobre Técnica e prática do Graffiti)

"Ele surgiu no bagulho, como se diz aí, no metrô né?" [referindo-se ao surgimento desta modalidade de arte urbana] (História do Graffiti)

Comentários favoráveis também partiram dos adolescentes espontaneamente ao longo da intervenção, principalmente após o início das atividades práticas (quarto encontro).

Desde o início, houve preocupação dos coordenadores em construir uma relação de proximidade e troca com os participantes. Isso foi feito por meio de falas sobre a trajetória do psicólogo citando histórico com conflitos com a lei (pixação), além de linguagem próxima à utilizada pelos jovens "na rua". Os relatos dos adolescentes, no grupo focal, corroboram com isso, uma vez que eles se referem ao coordenador de maneira bastante próxima, utilizando gírias para referenciá-lo (por exemplo: "Esse R é um louco!"). Essa visão, no entanto, sucede um primeiro momento de estranheza, em que os jovens supõem que ele havia chegado à unidade "meio com medo", apreensivo (categoria com 1,65\%, $\mathrm{n}=2$ ).

Também é percebido o envolvimento e o papel ativo dos adolescentes, em ações em que eles mesmos relatam que fizeram durante as oficinas, categoria com $5,79 \%$ ( $n=7$, por exemplo: "Eu ia lá na caneta"). Nos diários de campo, constatouse o crescimento gradual da participação e protagonismo dos jovens nas oficinas, por meio de falas e posicionamentos nas discussões, apropriação da técnica do graffiti e processo de construção do desenho. Há indícios, portanto, de que foi criado espaço de expressão para os jovens (colocando em pauta singularidade e contexto social de cada um) e possibilidade de diálogo com outros adolescentes, estagiárias e agentes socioeducativos.

Outro ponto que surgiu na análise dos grupos focais é o caráter cultural das atividades. A esse respeito, nota-se que se trata de uma modalidade de arte que faz parte do universo jovem e, de certo modo, transgressor, conquistando o público adolescente com certa facilidade. Isso pode ser verificado nas opiniões favoráveis dos participantes, quando foram exibidas imagens de arte urbana na apresentação de PowerPoint levada no grupo - categoria Opinião positiva sobre a arte do graffiti, com 2,48\% ( $n=3$, como "Essa aí ficou monstro, né?"). Em comentários espontâneos, os participantes disseram, ainda, que se interessavam pela temática - evidenciando identificação com elementos da cultura hip hop (RAP e graffiti). Assim, a proposta caminhou na direção de reflexões que fizessem parte da realidade - potente, ainda que marginalizada - dos jovens, sobretudo em contextos periféricos.

Um dos participantes afirmou, sobre as oficinas, que "ajuda a distrair a mente" (Opinião geral sobre as oficinas), com $0,83 \%(n=1)$. É interessante observar que 
em outro estudo, a respeito das atividades de lazer em uma unidade socioeducativa de internação do interior de São Paulo, a expressão "distrair a mente" também foi utilizada para caracterizar o lazer como aquilo que faz os adolescentes pararem de pensar sobre a privação de liberdade por algum tempo (da-Conceição \& Cammarosano-Onofre, 2013). Nos diários de campo, tal caráter é percebido principalmente nos dias com atividades mais livres (encontros 3, 4 e 6), com música e/ou a presença de convidados. Em sentido semelhante, surgiu uma menção à liberdade (0,83\%, na categoria outros), quando um adolescente disse "Só a Lili, né?" (forma de se referir à liberdade).

Corroborando para o papel das oficinas como atividade cultural, os Graffitis contribuíram para gerar reflexões dentre os participantes, o que pode ser constatado a partir da categoria Opinião sobre os Graffitis finais. Nesse sentido, houve falas que explicitamente demonstram este caráter reflexivo $(2,48 \%, n=3)$ outras que revelam confusão $(1,65 \%, \mathrm{n}=2)$, além de aparecerem opiniões positivas $(4,96 \%, n=6)$ e negativas $(2,48 \%, n=3)$. Falas que exemplificam tais categorias são:

"O bagulho ali, o cara viaja, né?" (Reflexão a partir dos desenhos) "Que viagem, né? Fizeram, daí jogaram tinta em cima, né?" (Confusão com os desenhos)

"Ficou baita!" (Opinião positiva dos desenhos)

"É, aquele negócio ali na arara ficou meio estranho, aquele bagulho escorrendo." (Opinião negativa dos desenhos)

Quanto à última frase, contudo, pontua-se que em conversa entre uma das estagiárias e os participantes (registrado em diário de campo), surgiu a hipótese de que a tinta escorrendo por cima do desenho das araras pudesse representar uma gaiola, tendo novas repercussões.

Por conseguinte, sugere-se que as oficinas se utilizaram de um recurso cultural para promover espaços de lazer e reflexão dentro da instituição, com caráter pedagógico, semelhante a Lima-Duarte et al. (2019). Nesse sentido, aproxima-se da perspectiva de da-Conceição e Cammarosano-Onofre (2013), os quais defendem a promoção de espaços de educação pelo e para o lazer dentro de unidades de privação de liberdade, em detrimento da utilização da retirada dos espaços de lazer como punição (medida disciplinar) para o descumprimento de regras pelos adolescentes (o que também ocorria na unidade investigada aqui).

Os vínculos estabelecidos entre os jovens e a coletividade $(0,83 \%)$ criada se revelam, por exemplo, na fala de um adolescente ao ver imagens da apresentação de PowerPoint do grupo de participantes em um dos encontros: "Aí, tá a tropa do R7" (referindo-se ao DJ R7, produtor de funk brasileiro). Além disso, em um momento de tensionamento/disputa a respeito da pintura do muro (que será detalhado adiante), os adolescentes conversaram entre si para tomar a decisão de realizar tal atividade (antes do encontro 5), mesmo com a existência de uma regra nas facções contra "pintar cadeia", por entenderem que isso fazia 
parte do processo das oficinas (Acordo coletivo entre o grupo de adolescentes, com 3,31\%, $n=4)$ :

"Foi tudo conversado entre tudo nós..." [sic].

Nos diários de campo, os vínculos entre os jovens foram percebidos pelo maior espaço de fala dado a adolescentes que anteriormente eram menos integrados ao grupo. Nos momentos de atividades grupais, voltadas para a construção de um projeto em comum (encontros com o desenho do graffiti nos muros), contribuiu-se para a formação de um coletivo (Lapassade, 1983). O grupo, inclusive, parecia ter um líder - adolescente que evadiu e, por isso, não participou dos últimos encontros da oficina, mas continuou a ser citado pelos colegas.

Em certas atividades, houve a participação de alguns agentes socioeducativos. Entretanto, a relação com eles era bastante ambígua e tensionada, ora predominando a hostilidade para com eles, ora predominando, ainda que de modo velado, uma relação de proximidade e afeto. Nos comentários sobre as imagens do PowerPoint, alguns destacaram opiniões positivas sobre um desenho feito por um agente socioeducativo (encontro 3 ), categoria com $2,48 \%(n=3)$. Por outro lado, colocam-se em patamar diferenciado ao ver a foto com todos os participantes do encontro seguinte: "Por que deixaram o Seu ir lá?", sendo que "Seu" se refere a um agente (categoria com 1,65\%, n=2). Essa ambivalência pode ter decorrido da relação de poder entre os dois papeis (agentes socioeducativos vs. internos), ou mesmo pelos atritos que decorreram das oficinas de Graffiti.

Uma hipótese que surgiu antes da análise dos grupos focais era que os participantes evitariam falar opiniões negativas, pois - supostamente, na concepção destes - isso poderia influenciar a avaliação técnica feita pela equipe e enviada ao juiz para analisar a continuidade ou término da medida de internação. De fato, até este momento, foram descritas apenas opiniões favoráveis - que predominaram no início do grupo focal e podem revelar um viés. Os participantes demoraram a emitir opiniões que demonstrassem algum tipo de tensão ou ambivalência, de modo que nada foi dito nesse sentido durante as oficinas. Alguns acontecimentos, como atitudes dos agentes socioeducativos em relação aos adolescentes (broncas e ameaças) durantes as semanas, só foram relatadas a partir de certo ponto do grupo focal.

Outra suspeita que emergiu da análise dos diários de campo (principalmente devido à resistência dos agentes socioeducativos em relação à proposta das oficinas) é que todo este processo geraria tensionamentos nas relações dentro da unidade. Isso foi verificado por meio das categorias de análise, de diferentes formas. Em primeiro lugar, há falas que foram ditas pelos adolescentes em tom positivo, mas que revelam indícios de que suas ações podem gerar atritos com as normas da unidade. Nos aprendizados, isso aparece em uma ação decorrente da oficina, quando um adolescente aponta que "já chega lá no barraco [quarto] e pixa tudo!" $(0,83 \%, \mathrm{n}=1)$. 
Quanto à atividade de teste dos sprays (terceiro encontro), isso também se evidencia. Neste dia, os adolescentes desviaram a atenção do desenho que estava sendo proposto pelo coordenador (pássaro) e começaram a escrever nomes, apelidos e palavras nos muros - o que foi interpretado como uma violação de regra pelos agentes. Entretanto, este acontecimento foi visto de maneira diferente pelos coordenadores da oficina. Quando os jovens começaram a escrever nos muros, o psicólogo propôs um acordo de que não poderiam ser escritas palavras relacionadas às facções, uma vez que os agentes e a equipe técnica "condenavam tal atitude". Então, um dos participantes, antes mesmo de conversar com o colega, apagou uma inscrição na parede. Dessa forma, foi avaliado que havia uma relação de confiança e ética entre coordenadores e participantes.

Nos momentos em que os jovens demonstram caráter mais ativo, verifica-se tom de dominância nas falas e, segundo relatos posteriores, esse evento da inscrição de nomes nas paredes gerou reações negativas nos agentes socioeducativos. Os relatos de ações com tal especificidade foram agrupados na categoria Ações de dominância dos adolescentes - Papel ativo dos adolescentes $(4,13 \%, n=5)$. Os próprios participantes demonstraram ambiguidade sobre este evento, em falas que compõem a categoria Tensionamento ou ambiguidade, nas Opiniões gerais sobre as oficinas $(4,96 \%, n=6)$. Nesse sentido, são citados os exemplos:

"Foi o dia que a gente arregaçou aqui!" (Ações de dominância dos adolescentes)

"Esse dia foi doido" (Tensionamento ou ambiguidade)

No grupo focal, os participantes contaram como foi tal reação dos agentes após o terceiro encontro (tensionamento por parte dos agentes - broncas e ameaças, com $4,13 \%, n=5)$, os quais mudaram sua postura em relação aos internos:

"Do outro dia só dava Seu de cabeça virada"

"Engrossaram e falaram um monte aí."

Inclusive, é deste acontecimento que desdobra aquilo que parece ser o ponto principal da discussão do grupo focal: o tensionamento gerado com os agentes e as formas como isso afetou os adolescentes (44,6\% das falas analisadas). Com fins de contextualização, será exposta a sequência dos acontecimentos com base nos diários de campo e nas falas dos adolescentes.

Os participantes do grupo focal relataram que havia sido feito um Acordo geral (Acordos coletivos e tensionamentos): iriam pintar as paredes para que fosse feito o graffiti final ("Vamos pixar o que for pintado...", categoria com 4,96\%, n=6). Tal combinado envolvia os adolescentes e os coordenadores da oficina, inicialmente com aval da equipe técnica e dos agentes. Como foi comentado, os jovens decidiram entre si que poderiam pintar as paredes em preparação para o graffiti com base naquele trato (Acordo coletivo entre o grupo de adolescentes). Isso porque "pintar os muros da unidade" não é bem visto pelos colegas do 
"mundão" (colegas associados à criminalidade que não estão em internação): "Não, porque não pode, dona! Se ia pintar cadeia. Num pode!" [sic] (Regras do Relação com o crime, com 1,65\%, $n=2$ ), sendo que não há flexibilidade nessas regras ("Num dá nem muito de sair pedindo opinião!"). Essa relação de autoridade distingue-se, portanto, do que parece ter ocorrido no processo das oficinas: conversas e acordos entre os próprios adolescentes, próximo à ética das relações (Brito, 2016).

Os jovens complementaram dizendo que "todo mundo tem uma vida lá fora, né?" (Menção à vida "lá fora" da internação, categoria com 4,13\%, $n=5$ ), assim como os Riscos que correm, caso alguém descubra o que aconteceu $(5,79 \%, n=7)$. Comentam também que querem mudar (categoria Tentativa de sair da vida do crime, com 3,31\%, $n=4)$ : "quero mudar minha vida, quero seguir outro caminho, mas..." há riscos dos colegas antigos virem "cobrar". Esse processo é bastante relevante tendo em vista a proposta de reflexões sobre ética das oficinas, pois evidencia as tentativas de se tomar decisões coletivas e mais autônomas (sem tantas regras rígidas e delimitadas por outrem), concomitantemente com as dificuldades dentro e fora da unidade para que essas tentativas tenham sucesso.

Após a pintura dos muros, em consequência das reações negativas dos agentes socioeducativos, a equipe técnica decidiu que apenas uma parede do solário poderia ser graffitada (sendo que as quatro paredes haviam sido pintadas em preparação para receber o graffiti). Diante disso, os adolescentes expressaram descontentamento e houve uma tentativa de negociação destes com o psicólogo e a equipe, assim como do psicólogo com os agentes e equipe técnica. Foi decidido, então, que duas paredes seriam pintadas. Os adolescentes entenderam que este episódio se configurou como um Descumprimento dos acordos coletivos (categoria com 3,31\%, $n=4$ ):

"Falaram uma coisa pra nós, aí chegou na hora e foi outra, né?" [sic].

Tanto que houve comentários com opiniões ambíguas sobre as oficinas (Opinião geral), assim como ao ser citada a possibilidade de novas oficinas acontecerem (categoria com 3,31\%, $n=4$ ), houve reações ambivalentes: alguns enfatizaram que já queriam estar fora da unidade, outros que não participariam ou que pixariam tudo (mesmo em desacordo com as regras).

Os participantes também passaram um grande tempo discutindo de quem era a culpa por aquela "quebra de acordo", fazendo Suposições sobre a impossibilidade de cumprir com o combinado. Em torno disso, houve uma diversidade de opiniões: alguns estavam em Dúvida $(0,83 \%, \mathrm{n}=1)$, outros sugeriram ser as profissionais da Equipe técnica $(0,83 \%, \mathrm{n}=1)$, mas contra isso, havia vários argumentos $(3,31 \%, n=4$, como "Mas pras donas que ficam lá na frente, só vem aqui uma vez por semana..." [sic] - e, por isso, não se importariam tanto com os graffitis feitos). A maior parte dos adolescentes entendeu que esse descumprimento teria decorrido da reação dos agentes socioeducativos (1,65\%, 
$\mathrm{n}=2$ ), principalmente porque eles manifestaram visão negativa sobre as oficinas $(4,96, n=6)$. Supondo uma fala de um agente, um adolescente disse: "Tá vendo esse louco aí, ele não sabe pixar! Deixou os guri fazer, imagina no dia que for..." [sic]. Não obstante, após a arte final, os agentes tiveram uma visão positiva sobre os graffitis (posterior - mudança de visão, categoria com 2,48\%, $\mathrm{n}=3$ ).

Outros comentários que surgiram se referem a autoimagem dos adolescentes $(1,65 \%, n=2)$ : ao se verem nas fotos do PowerPoint, disseram que achavam que estavam gordos; e opiniões positivas sobre os graffiteiros convidados $(0,83 \%, n=1)$.

Com base nos elementos apontados, conclui-se que a proposta se afasta de uma visão tutelar do papel do estado em relação aos adolescentes em cumprimento de medidas socioeducativas (Garcia \& Pereira, 2014), assim como de posturas moralizantes. Aposta-se, portanto, no protagonismo e potencialização dos sujeitos, consonantes com a perspectiva da Psicologia Social. Embasado em perspectiva ética (Brito, 2016), os acontecimentos que surgiram promoveram discussões sobre responsabilização, bem como a integração social dos jovens a partir de posicionamentos outros. Dessa forma, houve movimentos na direção de dois dos objetivos das medidas socioeducativas (Presidência da República, 1990, 2012).

\section{ALA FEMININA}

Nesta ala, os diários de campo também evidenciaram conversas sobre as regras dentro e fora da instituição (por exemplo, uma participante falou da dificuldade de questionar as coisas na internação) e algumas adolescentes demonstraram grande interesse por arte urbana, como Rap, graffiti e até tatuagens. Entretanto, houve uma dificuldade em se trabalhar com os subgrupos separadamente, em momentos diferentes ou através das grades, nos momentos conjuntos.

Quanto ao graffiti final (Figura 2), foram feitos desenhos de uma águia (ideia solicitada pelas adolescentes, para representar liberdade), letras, personagens (duas mulheres), stencils variados (moldes vazados de figuras a serem preenchidas com spray), um painel com diversos escritos e outros desenhos das jovens. Novamente nesta ala, a maior parte das imagens foram desenvolvidas pelos/as grafiteiros/as convidados/as, incentivando a participação das adolescentes, para fazer algumas partes específicas. Além disso, as participantes fizeram muitos desenhos com stencil e palavras no painel (promovido pelo coordenador). 


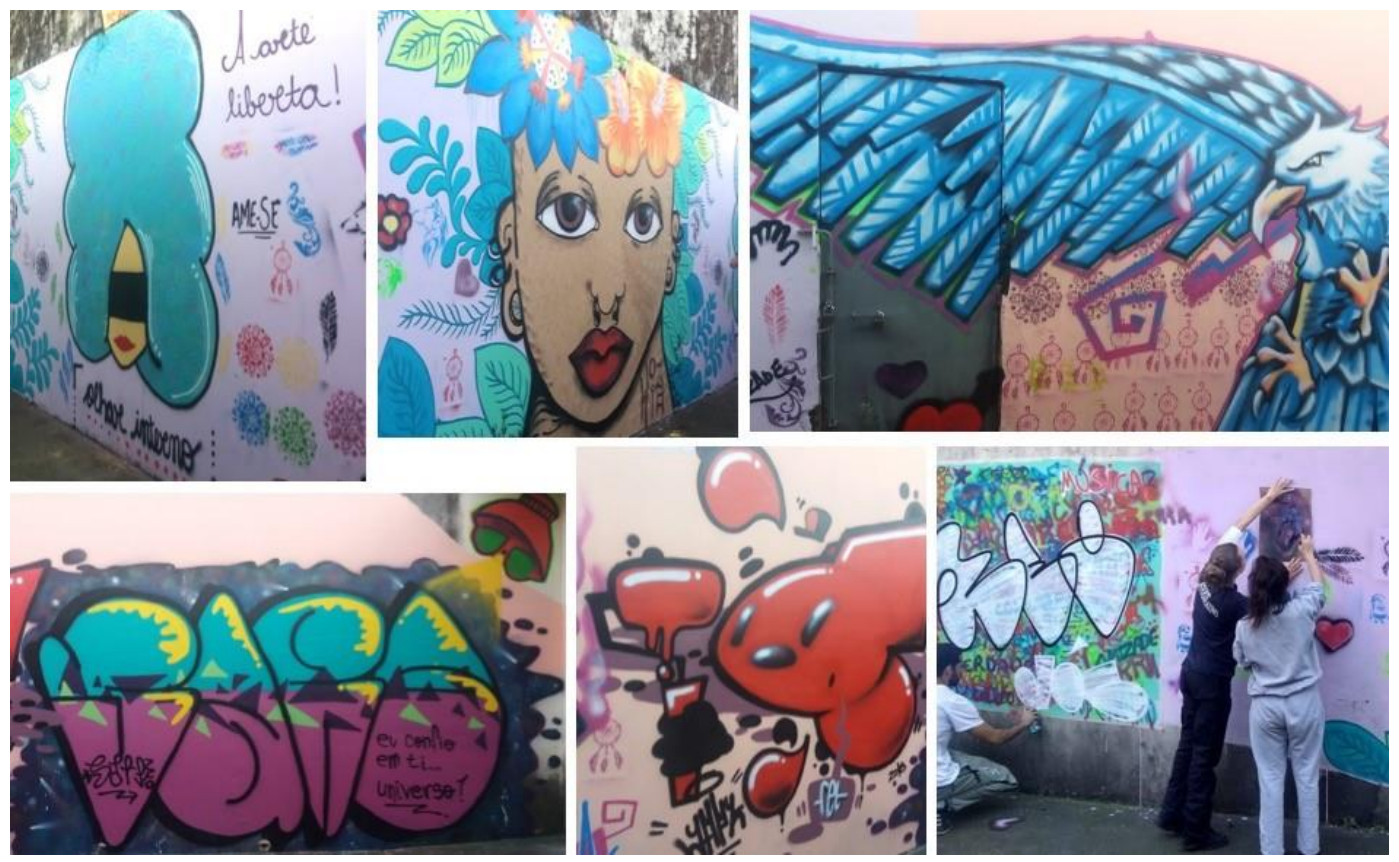

Figura 2.

Graffitis realizados na ala feminina. Da esquerda para a direita, na linha superior, o trabalho dos artistas: Mandinn, Koiza, Amapá. Na linha inferior, os trabalhos de Sari e Japz, e uma imagem do psicólogo coordenador, uma agente socioeducativa e uma adolescente fazendo pinturas.

Em relação à análise de conteúdo do grupo focal na ala feminina, houve diversas opiniões positivas sobre a intervenção. Muitas das adolescentes disseram que gostariam que as oficinas continuassem, prioritariamente com o Graffiti, ao ser sugerido que outros temas da arte urbana fossem abordados. Elas expressaram visões bastante favoráveis, de forma geral ("Pra mim, foi ótimo. Curti bastante!" [sic]) ou especificamente sobre algum dos encontros.

Em referência aos graffitis finais, a maior parte das opiniões também foram positivas. Foi indicado qual desenhos cada adolescente mais gostou: a maior parte citou desenhos feitos pelos convidados: "águia", "pokemon" e apenas uma delas disse que seu preferido era um desenho feito em conjunto com o psicólogo coordenador das oficinas. Não obstante, uma adolescente pontuou uma dúvida ou confusão quanto a um dos graffitis: questionou o tamanho do cabelo representado por um desenho (canto superior esquerdo na Figura 2), o qual possivelmente fazia alusão a um cabelo estilo black.

Assim como na ala masculina, também tiveram boas impressões sobre o psicólogo que conduziu as oficinas, dizendo que ele era "dahora". Os termos utilizados em tais falas demonstram certa identificação e relação de proximidade com os coordenadores. Alguns comentários evidenciaram, ainda, que as oficinas funcionaram como espaço de lazer e reflexão, expressa nas falas:

"É massa. Ainda mais desenhar escutando um som. É mil grau!" [a respeito do terceiro encontro] 
"Só falta desenhar a gaiola. Ele está triste, parece que está preso." [em relação a um desenho do pássaro, feito durante o teste dos sprays]

De maneira similar à análise do grupo masculino, surgiu a hipótese de que as opiniões das participantes estariam enviesadas, ou seja, que as jovens evitariam dar opiniões negativas. Neste caso, com um fator agravante: durante todo o processo das oficinas, assim como no grupo focal, houve presença constante de agentes socioeducativas de forma mais próxima e com maior controle (devido ao número reduzido de adolescentes meninas), que podem ter inibido algumas falas e interações, ou até mesmo reflexões. De fato, nesta ala houve menos discussões que evidenciassem tensões ou disputas, bem como expressões desfavoráveis à intervenção. Outra hipótese seria que isso decorreria de diferenças de gênero na relação das adolescentes entre si, com criminalidade e o cumprimento de medidas socioeducativas - mas não há elementos suficientes para chegar a uma conclusão a este respeito.

Nessa direção, a relação com as regras e acordos foi um diferencial. Surgiram apenas duas falas sobre o tema durante o grupo focal: uma dizendo que quase se infringiu uma regra e outra que teve falta de opção para a escolha das cores para pintar os muros. Respectivamente:

\section{"Quase que eu pixei o muro com meu bairro"}

"Nem escolhi, né? (risos) Era a única opção [de cor]"

Alguns pontos com conotação negativa foram citados, mas em número bastante reduzido. Uma participante comentou que não gostou de ver sua imagem na apresentação exibida ("Por que essa foto, dona? Que desacato" risos), revelando preocupação com sua autoimagem. Houve comentários autodepreciativos sobre a própria técnica das adolescentes na pintura/ graffiti, que não haviam surgido na ala masculina, por exemplo: "Se fosse pra mim ser pintora, eu ia ser pobre" [sic]. A respeito dos graffitis realizados durante o quarto encontro (teste de sprays), elas ficaram comparando o que cada subgrupo realizou (pássaro e árvore). Por fim, duas participantes ficaram com raiva por terem perdido um jogo de futebol da Copa do Mundo, que aconteceu no dia na oficina final e, por isso, não foram autorizadas a assistir pelas agentes socioeducativas.

A obrigatoriedade na participação das oficinas, assim como a impossibilidade de juntar as duas alas femininas durante os encontros foram analisadas como duas limitações da intervenção. Adicionalmente, foram notadas diferenças na participação do primeiro e do segundo subgrupo, sendo que as adolescentes que viram o início participaram mais do que aquelas que viram a conclusão dos desenhos. Como já mencionado, o trabalho com os subgrupos separados, neste e em outros momentos, dificultou a comunicação e dinâmica grupal.

Outra questão singular dessa ala foi o vínculo mais próximo que as participantes desenvolveram com os graffiteiros voluntários, inclusive sendo incentivadas pela equipe técnica da unidade a escreverem cartas agradecendo-os. No grupo focal 
foram feitos comentários como: "Oh, mas os cara [graffiteiros voluntários] manja pra $c^{\star \star \star}$ desse negócio!" [sic] Disseram que gostariam que eles retornassem para futuros encontros e oficinas. Uma das adolescentes, com bastante afinidade para desenho e arte urbana, disse que gostaria de fazer um trabalho em conjunto com um dos voluntários.

A relação com as graffiteiras mulheres, de acordo com os registros em diário de campo, parecem ter tido conotação identificatória, enquanto com os homens houve certo interesse afetivo. A preocupação em convidar artistas mulheres surgiu das estagiárias ao notarem um desconforto das adolescentes com o fato de que só havia exemplos de graffiteiros homens. O tema gênero e arte urbana também foi abordado no grupo temático de psicologia, desenvolvido em outro momento pelas estagiárias, fomentando uma relação mais próxima e maior participação destas na coordenação das oficinas dessa ala.

No final da atividade, ao serem questionadas sobre sugestões para oficinas futuras que poderiam acontecer na instituição, foi indicado: "filtro dos sonhos", "artesanato", "argila", além de maior frequência das atividades ("mais vezes na semana"). As participantes estavam bastante animadas que haveria, na semana seguinte, uma confraternização de fechamento das oficinas, com todos os envolvidos (adolescentes, equipe técnica, gerência, funcionários do departamento de administração socioeducativo, coordenadores das oficinas e convidados) e, a respeito disso, comentaram: "O que importa é que vai ter uma despedida do graffiti" e que iriam "tirar a barriga da miséria".

\section{CONSIDERAÇÕES FINAIS}

Avalia-se que a intervenção contribuiu para o caráter socioeducativo da medida de internação, uma vez que promoveram protagonismo dos/das adolescentes, vínculos positivos e reflexões sobre escolhas e responsabilização. Por meio das oficinas de graffiti, que possibilitaram a problematização das relações, foi possível inserir elementos que partiram dos/as próprios/as adolescentes na construção do local que habitam: na escolha de temas dos desenhos e na execução das pinturas.

Adicionalmente, foram tensionados os espaços de fala dos jovens e diálogo com os agentes. Em um local onde opera, majoritariamente, a lógica da lei e da punição, houve uma ruptura: foi proposta a reflexão ética (sobre escolhas e implicações), estética (pela criação e desconstrução de relações cristalizadas, entre adolescentes e equipe da instituição) e política (posicionamentos dos jovens diante dos atos, com seus riscos e potências) (Brito \& Zanella, 2017). Consequentemente, contribuiu-se para a constituição de novos acordos, novos horizontes. Para tal, foi essencial a utilização do dispositivo do grupo, que produz acontecimentos e imprevisibilidades, os quais promovem deslocamentos nas relações (Rodrigues \& Lopes de Oliveira, 2018). 
Dessa forma, contribuiu-se para o caráter socioeducativo da medida e foram respeitados os direitos e a condição de pessoa em desenvolvimento dos/das adolescentes, coerente com as perspectivas do ECA e do SINASE (Presidência da República, 1990). Acredita-se, ainda, que a intervenção vai na direção de Mansur et al. (2018), os quais clamam pela necessidade de que sejam desenvolvidas políticas que promovam cidadania, redes de apoio e acesso a cultura, educação e lazer nesse contexto.

Por outro lado, também foram gerados tensionamentos na visão dos agentes socioeducativos, que inicialmente relataram que reconheciam seu papel como o de "impor limites". Tal posicionamento se aproxima com o que é relatado por Leal e Macedo (2019) sobre os trabalhadores de uma unidade de internação de Teresina-PI, de uma crença de que a adesão às rotinas institucionais fosse alterar os valores sociais dos jovens. Por meio das oficinas e das reuniões realizadas durante as intervenções, possibilitou-se a reflexão de que a simples imposição das normas previamente estabelecidas e punição das infrações não é a única saída e, talvez, uma das que menos convoca à reflexão, ainda que necessária em alguns momentos. Embora as normas de organização do local possam ter papel importante na segurança, elas acabam muitas vezes por contribuir apenas com a desaprovação da conduta infracional - restringindo-se a um dos objetivos das medidas socioeducativas (Presidência da República, 1990, 2012). Para garantir o caráter socioeducativo, é preciso que sejam criados espaços de fala com os/as adolescentes, de experimentação e de desconstrução de relações cristalizadas.

Por fim, também houve mudanças na relação entre equipe técnica e agentes socioeducativos. Embora trabalhem no mesmo local, a cultura da instituição, por vezes segregacionista, faz com que pareça que compõem equipes distintas, inviabilizando diálogos e reuniões conjuntas. No processo das oficinas, foi possível estabelecer maior espaço de trocas entre agentes e técnicos, por meio das reuniões e negociações sobre o andamento das oficinas. Não obstante, esse processo nem sempre se deu de forma contínua ou exitosa, sendo que, em alguns momentos, prevaleceram decisões estabelecidas hierarquicamente. Por exemplo, os agentes disseram que só aceitaram as "pixações" dos apelidos dos adolescentes dos muros (no quarto encontro, de experimentação dos sprays) porque havia sido uma decisão da gerência.

Não foi possível constatar em que medida as oficinas, de fato, mudaram as relações entre cotidianas entre agentes, equipe técnica e adolescentes, mas espera-se que haja transformações, uma vez que foram produzidas evidências nesse sentido. A partir da inserção do psicólogo na unidade, bem como do interesse expressado por alguns dos graffiteiros convidados, no segundo semestre de 2018, continuou-se o trabalho socioeducativo na unidade, por meio de outras modalidades de arte urbana.

A presente pesquisa teve algumas limitações, sendo destacadas a impossibilidade de gravar o grupo focal realizado na ala feminina, bem como outras restrições já 
pontuadas decorrentes de decisões da gerência e equipe da unidade. Sugere-se que, em estudos futuros, aprofunde-se a investigação de questões de gênero, bem como da relação entre adolescentes, equipe técnica e agentes socioeducativos. Espera-se, ainda, que futuras pesquisas e/ou relatos de experiências investiguem e discutam intervenções psicossociais criativas, que reconheçam a potência do trabalho coletivo e que visem contribuir de forma ético-política com a transformação dos sujeitos adolescentes em cumprimento de medidas de internação. Como apontado por Coscioni e colaboradores (2017), diante do conhecimento do caráter punitivo das medidas socioeducativas, é fundamental que as pesquisas investiguem elementos que contribuam para a transformação desse contexto, assim como para promover o desenvolvimento saudável durante a privação de liberdade.

\section{REFERÊNCIAS}

Almeida, G. B. (2013). Política, subjetividade e arte urbana: O graffiti na cidade (Dissertação de Mestrado). Universidade Federal de Santa Catarina, Florianópolis, SC.

Bardin, L. (1977). Análise de conteúdo (L. A. Reto \& A. Pinheiro, Trans.). Lisboa, Portugal: Edições 70.

Berri, B., Zanella, A. V., \& Assis, N. (2015). Imagens da cidade: O projeto ArteUrbe. Revista Polis e Psique, 5(2), 123-149. https://doi.org/10.22456/2238-152X.53951

Brito, R. V. A. (2016). Jovens, arte e cidade: A via de mão tripla (Dissertação de Mestrado). Universidade Federal de Santa Catarina, Florianópolis, SC.

Brito, R. V. A \&, Zanella, A. V. (2017). Formação ética, estética e política em oficinas com jovens: Tensões, transgressões e inquietações na pesquisa-intervenção. Bakhtiniana: Revista de Estudos do Discurso, 12(1), 42-64. https://doi.org/10.1590/2176-457326093

Broide, J., \& Broide, E. E. (2015). Do silêncio à palavra. In J. Broide \& E. E. Broide, A psicanálise em situações sociais críticas: Metodologia clínica e intervenções (pp. 13-26). São Paulo, SP: Escuta.

Conselho Nacional do Ministério Público. (2019). Panorama da execução dos programas socioeducativos de internação e semiliberdade nos estados brasileiros. Brasília, DF: CNMP.

Coscioni, V., Costa, L. L. A., Rosa, E. M., \& Koller, S. H. (2017). O cumprimento da medida socioeducativa de internação no Brasil: Uma revisão sistemática da literatura. Psico, 48(3), 231-242. http://dx.doi.org/10.15448/1980-8623.2017.3.24920

Deleuze, G. (2002). Espinosa: Filosofia prática (D. Lins \& F. P. Lins, Trans.). São Paulo, SP: Escuta. (Trabalho original publicado em 1970).

Frota, A. M. M. C. (2007). Diferentes concepções da infância e adolescência: A importância da historicidade para sua construção. Estudos e Pesquisas em Psicologia, 7(1), 147-160.

Garcia, J., \& Pereira, P. (2014). Somos todos infratores. O Social em Questão, 18(31), 137-162.

Gesser, M. (2013). Políticas públicas e direitos humanos: Desafios à atuação do psicólogo. Psicologia: Ciência e Profissão, 33(spe), 66-77.

Grassi, G. O., Coltro, B. P., Giacomozzi, A. I., \& Santa Rosa, T. R. (2019). O trabalho do psicólogo com grupo de adolescentes em privação de liberdade. Estudos Interdisciplinares em Psicologia, 10(3), 228-242. http://dx.doi.org/10.5433/2236-6407.2019v10n3p228

Lapassade, G. (1983). Dialética dos grupos, das organizações, das instituições. In Grupos, organizações e instituições (H. A. A. Mesquita, Trans., 2nd ed., pp. 226-253). Rio de Janeiro, RJ: Francisco Alves.

Leal, D. M., \& Macedo, J. P. (2019). Os discursos protetivos e punitivos acerca dos adolescentes em medida de internação no Brasil. Revista Latinoamericana de Ciencias Sociales, Niñez y Juventud, 17(1), 207-221. https://doi.org/https://dx.doi.org/10.11600/1692715x.17112

Lima-Duarte, F. K., Gaia, R. V., Torres-Filho, J. G., \& do Nascimento, D. R. (2019). Ensino do gênero grafite: Uma experiência com adolescentes em privação de liberdade. Imagens da Educação, 9(1), 111-126.

Mansur, T. S., Nascimento, D. B., Rosa, E. M., \& Merçon-Vargas, E. A. (2018). Brazilian adolescent offenders' characteristics and the contexts of institutions for young offenders: A literature 
review. In C. Pracana \& M. Wang (Eds.), Psychology applications \& developments IV (Advances in Psychology and Psychological Trends Series, pp. 241-252). Lisboa, Portugal: InScience Press.

Ministério dos Direitos Humanos. (2018). Levantamento anual SINASE 2016. Brasília, DF: Ministério dos Direitos Humanos.

Presidência da República. Casa Civil. Subchefia para Assuntos Jurídicos. (1927). Decreto $n^{\circ} 17.943-A$ de 12 de outubro de 1927. Consolida as leis de assistencia e protecção a menores. Código de Menores. Rio de Janeiro, RJ. Disponível em http://www.planalto.gov.br/ccivil_03/decreto/1910-1929/d17943a.htm

Presidência da República. Casa Civil. Subchefia para Assuntos Jurídicos. (1990). Lei n 8.069, de 13 de julho de 1990. Dispõe sobre o Estatuto da Criança e do Adolescente e dá outras providências. Brasília, DF. Disponível em http://www.planalto.gov.br/ccivil_03/leis//8069.htm

Presidência da República. Casa Civil. Subchefia para Assuntos Jurídicos. (2012). Lei $n^{\circ} 12.594$, de 18 de janeiro de 2012). Institui o Sistema Nacional de Atendimento Socioeducativo (Sinase), regulamenta a execução das medidas socioeducativas destinadas a adolescente que pratique ato infracional e dá outras providências. Brasília, DF. Disponível em http://www.planalto.gov.br/ccivil_03/_ato2011-

2014/2012/lei//12594.htm\#: :text=Art.,adolescente\%20que\%20pratique\%20ato\%20infraci onal.

Rodrigues, D. S., \& Lopes de Oliveira, M. C. S. (2018). Grupo como dispositivo socioeducativo: Pesquisa-intervenção com adolescentes em cumprimento de prestação de serviço à comunidade. Revista De Psicologia, 9(1), 30-41.

Silva, M. A., \& Meira, M. R. (2014). Por uma ética de integridade e produção de sentidos na atenção a adolescentes infratores. EccoS - Revista Científica, 34, 131-142. https://doi.org/10.5585/eccos.n34.4157

Simões, P. (2014). Garantindo direitos: Um estudo do sistema socioeducativo em Santa Catarina Política \& Sociedade, 13(26), 11-34. http://dx.doi.org/10.5007/2175-7984.2014v13n26p11

Spinoza, B. (2014). Ética (T. Tadeu, Trans.). Belo Horizonte, MG: Autêntica Editora. (Trabalho original publicado em 1677).

Scisleski, A. C. C., Bruno, B. S., Galeano, G. B., Santos, S. N., \& Silva, J. L. C. (2015). Medida socioeducativa de internação: Estratégia punitiva ou protetiva? Psicologia \& Sociedade, 27(3), 505-515. https://doi.org/10.1590/1807-03102015v27n3p505

\section{AGRADECIMENTOS}

Os autores agradecem ao Departamento de Administração Socioeducativo do Estado de Santa Catarina-DEASE pela aprovação e apoio à realização do projeto. Agradecem, ademais, ao restante dos profissionais da equipe técnica, aos agentes socioeducativos e aos adolescentes pela viabilização e participação na intervenção e pesquisa. Por fim, agradecem Alejandra Matiz pela tradução do título e resumo do artigo para o espanhol.

\section{CONFLITOS DE INTERESSES}

Os autores declaram que não possuem conflito de interesse de qualquer ordem, seja financeira, comercial, política, acadêmico e/ou pessoal.

\section{FINANCIAMENTO}

O Departamento de Administração Socioeducativo do Estado de Santa Catarina-DEASE forneceu financiamento para a compra de materiais para a realização das oficinas (tintas, rolos de pintura $e$ sprays). 


\section{SOBRE OS AUTORES}

Cláudia Regina Campos Rodrigues é psicóloga pela Universidade Federal de São Carlos, realizando período de mobilidade acadêmica na Universidade Federal de Santa Catarina em 2018-2019. Atualmente é residente pelo Programa de Saúde Mental da Universidade Estadual de Campinas. E-mail: claudiarcrodrigues@gmail.com

\section{(1) http://orcid.org/0000-0002-8599-3683}

Amanda Garcez é psicóloga pela Faculdade CESUSC. Atua como psicóloga clínica com viés psicanalítico e com adolescentes do Programa Jovem Aprendiz, através da instituição qualificadora RENAPSI.

E-mail: garcez.amanda@hotmail.com

\section{(2) https://orcid.org/0000-0003-1991-6169}

Renan De Vita Alves de Brito é professor do departamento de Psicologia da FURB - Fundação Universidade Regional de Blumenau, e doutorando em Psicologia pela Universidade Federal de Santa Catarina.

E-mail: renandvab@gmail.com

(2) https://orcid.org/0000-0001-6668-8088

Andréia Isabel Giacomozzi é psicóloga formada pela Universidade Federal de Santa Catarina-UFSC Mestre e Doutora em Psicologia pela UFSC, Professora do PPGP e do Departamento de Psicologia da UFSC, membro do LACCOS-Laboratório de Psicologia Social da Comunicação e Cognição.

E-mail: agiacomozzi@hotmail.com

(2) https://orcid.org/0000-0002-3172-5800

Tathiana Reche Santa Rosa é psicóloga formada pela Universidade Paulista Objetivo (UNIP), Mestre em Ciências da Educação pelo Instituto Superior de Educação Lúcia Dantas e atua no Departamento de Administração Socioeducativo de Santa Catarina- DEASE.

E-mail: santarosapsic@yahoo.com.br

(1) https://orcid.org/0000-0003-0590-9830 